\title{
AVALIAÇÃO DO ESFORÇO FÍSICO DESPENDIDO POR TRABALHADORES NAS ATIVIDADES DE COLHEITA DE ERVA- MATE (Ilex paraguariensis A. St.-Hil.)
}

\author{
Eduardo da Silva Lopes*, Danilo Martin Domingos**, Antonio José de Araújo***, \\ Nilton César Fiedler**** \\ *Eng. Florestal, Dr., Depto. de Engenharia Florestal, UNICENTRO - eslopes@irati.unicentro.br \\ **Eng. Florestal, Depto. de Engenharia Florestal, UNICENTRO - quevez@hotmail.com \\ ***Eng. Florestal, Ph.D., Depto. de Engenharia Florestal, UNICENTRO - dearaujo@onda.com.br \\ ****Eng. Florestal, Dr., Depto. de Engenharia Rural, UFES - fiedler@ufes.br \\ Recebido para publicação: 09/02/2006 - Aceito para publicação: 25/04/2006
}

\begin{abstract}
Resumo
Esta pesquisa objetivou avaliar o esforço físico despendido por trabalhadores nas atividades de colheita de erva-mate, na busca de melhorias nas condições de saúde, bem-estar, segurança, conforto e produtividade do trabalhador. Foi realizada em propriedades rurais localizadas na região centro-sul do estado do Paraná. Os dados foram obtidos por meio do levantamento da freqüência cardíaca no trabalho, com uso de um monitor Polar Oy e classificação do trabalho segundo metodologia proposta por Apud (1997). Os resultados indicaram que a maioria das atividades da colheita de erva-mate é classificada como de exigência física moderadamente pesada. Foram recomendadas algumas medidas ergonômicas no trabalho, com o objetivo de prevenir desgastes físicos dos trabalhadores.

Palavras-chave: Carga de trabalho físico; colheita erva-mate; ergonomia.
\end{abstract}

\begin{abstract}
Evaluation of the physical efforts applied by workers in harvesting operations of maté (Ilex paraguariensis A. St.-Hil.) leaves. The objective of this study was to evaluate the physical efforts applied by workers in harvesting operations of mate leaves, aiming at the improvement of their health, well-being, safety, comfort and productivity. It was carried out in farms, located in the centralsouthern region of Parana State. The data was collected by survey of the cardiac frequency during work using a Polar Oy monitor and classified in categories as proposed by Apud (1997). The results indicated that the majority of the activities of the mate leaves harvesting is classified as a moderately heavy physical effort. Some ergonomic recommendations were made in order to prevent physical strain on the workers.

Keywords: Physical effort; maté leaves harvesting; ergonomics.
\end{abstract}

\section{INTRODUÇÃO}

A preocupação com o bem-estar, a saúde e a segurança do ser humano no trabalho, seja esse leve ou pesado, vem aumentando nos últimos anos, pois quando o trabalho representa apenas uma obrigação ou necessidade, a situação é desfavorável tanto para o empregado quanto para o empregador (GRANDJEAN, 1988).

A erva-mate (Ilex paraguariensis A. St.-Hil.) constitui uma importante cultura em termos socioeconômicos, principalmente para as pequenas e médias propriedades rurais da região Sul do Brasil. Ela forma um dos sistemas agroflorestais mais característicos da região, sendo produzida em aproximadamente 600 empresas e 180 mil propriedades rurais, rendendo anualmente acima de R\$ 150 milhões aos produtores rurais (RODIGHERI, 1997).

No processo produtivo, a colheita da erva-mate é muito importante devido ao grande número de trabalhadores envolvidos. Ao contrário de outros países, onde se utilizam métodos mecanizados, no Brasil a colheita é realizada por métodos manuais, com uso de ferramentas rudimentares e expressivo uso de 
mão-de-obra de baixa qualificação. Além disso, os trabalhadores estão freqüentemente expostos ao desgaste físico e às condições ambientais desfavoráveis.

$\mathrm{Na}$ colheita da erva-mate, os galhos finos e folhas são cortados com auxílio de ferramentas manuais (facão, serrotes, tesouras, etc.), prensados em fardos denominados "ponches" ou amarrados com taquaras denominados "raidos", sendo então carregados manualmente nos veículos para o transporte até a indústria (RODIGHERI, 1997).

Segundo Iida (1990), a avaliação da carga física de trabalho foi o primeiro problema tratado pela fisiologia do trabalho, sendo uma questão central para a maioria dos trabalhadores, inclusive para aqueles que atuam em setores com maior nível tecnológico e com menores esforços físicos. Nesses estudos, medem-se os índices fisiológicos com o objetivo de determinar o limite de atividade física que um indivíduo pode exercer, de forma que seja possível determinar a duração do trabalho e a duração e a freqüência de pausas conforme a capacidade física do trabalhador.

Segundo Couto (1995), a carga de trabalho físico pode ser avaliada por meio da determinação do dispêndio energético da atividade ou por meio de índices fisiológicos como a freqüência cardíaca, expressa em batimentos por minuto (bpm) e determinada pela palpação de artérias ou com uso de medidores eletrônicos.

O limite de carga máxima no trabalho pode ser calculado indiretamente, com base na freqüência cardíaca do trabalho (FCT) ou na carga cardiovascular (CCV). A carga cardiovascular (CCV) corresponde à percentagem da freqüência cardíaca do trabalho (FCT) em relação à freqüência cardíaca máxima utilizável (FCM), a qual não deve ultrapassar $40 \%$ da freqüência cardíaca do trabalho (APUD, 1989).

A reorganização ergonômica do trabalho e a conseqüente aplicação prática de seus resultados podem levar a condições mais seguras e saudáveis no ambiente de trabalho, melhorando sensivelmente a adaptação da atividade à pessoa que a realiza e proporcionando-lhe um trabalho com maior conforto, bem-estar, produtividade e qualidade (FIELDER et al., 2003).

Esta pesquisa teve como objetivo avaliar a carga de trabalho físico exigida nas atividades de colheita de erva-mate em propriedades rurais da região centro-sul do estado do Paraná, visando fornecer subsídios para a reorganização do trabalho e melhorias nas condições de saúde, segurança, conforto e produtividade.

\section{MATERIAL E MÉTODOS}

\section{Área de estudo}

A pesquisa foi realizada em três propriedades rurais abrangidas pelo programa de fomento da indústria ervateira Baldo S.A., no município de São Mateus do Sul (PR). Os dados foram coletados nos meses de janeiro e julho de 2005 , por ocasião da safra de erva-mate na região. A temperatura e a umidade relativa máxima, média e mínima durante o período de coleta dos dados são mostradas na tabela 1.

Tabela 1. Temperatura e umidade relativa média nos meses de janeiro e julho na região de estudo. Table 1. Average relative humidity and temperature in January and July in the study region.

\begin{tabular}{lcccccc}
\hline \multirow{2}{*}{ Período } & \multicolumn{3}{c}{ Temperatura média $\left({ }^{\circ} \mathbf{C}\right)$} & \multicolumn{3}{c}{ Umidade relativa (\%) } \\
\cline { 2 - 7 } & Máxima & Média & Mínima & Máxima & Média & Mínima \\
\hline Janeiro de 2005 & 30,5 & 26,6 & 16,3 & 73,8 & 62,0 & 51,7 \\
Julho de 2005 & 17,9 & 14,3 & 7,8 & 87,7 & 70,6 & 58,7 \\
\hline
\end{tabular}

\section{População e amostragem}

O tamanho da amostra de trabalhadores e número mínimo de repetições utilizadas na pesquisa foi estabelecido com o uso da seguinte fórmula (CONAW, 1977).

$$
n \geq \frac{t^{2} \cdot s^{2}}{e^{2}}
$$


em que:

$\mathrm{n}=$ número de amostras ou pessoas necessárias;

$\mathrm{t}=$ valor tabelado em nível de 5\% de probabilidade (distribuição $\mathrm{t}$ de Student);

$\mathrm{s}=$ desvio-padrão da amostra.

\section{Coleta de dados}

A carga de trabalho físico foi obtida por intermédio do levantamento da freqüência cardíaca de uma amostra de 30 trabalhadores ao longo da jornada de trabalho (bpm), que atuavam nas seguintes atividades: poda, quebra de galhos, carregamento do veículo de transporte (abaixo) e carregamento do veículo de transporte (acima), conforme descrição apresentada na tabela 2.

Os trabalhadores que participaram da pesquisa tinham uma idade média de 33,3 anos, estatura média de $1,73 \mathrm{~m}$ e peso médio de $67,1 \mathrm{~kg}$, cujos dados foram levantados preliminarmente.

Tabela 2. Descrição técnica das atividades de colheita de erva-mate avaliadas.

Table 2. Technical description of the anise harvest activities evaluated.

\begin{tabular}{|c|c|c|}
\hline Atividade & Fases & Descrição \\
\hline \multirow{3}{*}{ Poda } & Principal & $\begin{array}{l}\text { O trabalhador realiza a poda de galhos de maior porte ou } \\
\text { densidade. }\end{array}$ \\
\hline & Secundária & $\begin{array}{l}\text { O trabalhador realiza a poda de galhos de menor porte ou } \\
\text { densidade. }\end{array}$ \\
\hline & Deslocamento & O trabalhador desloca-se entre as árvores a serem podadas. \\
\hline \multirow{4}{*}{$\begin{array}{l}\text { Quebra de } \\
\text { galhos }\end{array}$} & Apanhamento de galhos & $\begin{array}{l}\text { O trabalhador apanha os galhos que foram podados e que estão } \\
\text { dispostos sobre o terreno. }\end{array}$ \\
\hline & Corte de galhos & $\begin{array}{l}\text { O trabalhador faz o corte ou a quebra de galhos com auxílio de } \\
\text { facão para a posterior montagem dos feixes. }\end{array}$ \\
\hline & $\begin{array}{l}\text { Acomodação de galhos } \\
\text { no feixe }\end{array}$ & $\begin{array}{l}\text { O trabalhador faz a acomodação e organização dos galhos no } \\
\text { feixe. }\end{array}$ \\
\hline & Deslocamento & O trabalhador desloca-se entre os feixes a serem quebrados. \\
\hline \multirow{3}{*}{$\begin{array}{l}\text { Carregamento de } \\
\text { caminhão } \\
\text { (abaixo) }\end{array}$} & Rolagem de feixe & $\begin{array}{l}\text { O trabalhador situado no solo faz a rolagem do feixe de erva- } \\
\text { mate para próximo do veículo de transporte, onde será feita a } \\
\text { posterior pesagem e carregamento. }\end{array}$ \\
\hline & $\begin{array}{l}\text { Levantamento de feixe } \\
\text { para pesagem }\end{array}$ & $\begin{array}{l}\text { O trabalhador situado no solo levanta o feixe de erva-mate com o } \\
\text { auxílio de uma haste para posterior pesagem. }\end{array}$ \\
\hline & Pesagem de feixe & $\begin{array}{l}\text { O trabalhador situado no solo faz a pesagem do feixe de erva- } \\
\text { mate a ser carregado no veículo de transporte. }\end{array}$ \\
\hline \multirow{4}{*}{$\begin{array}{l}\text { Carregamento de } \\
\text { caminhão } \\
\text { (acima) }\end{array}$} & Apanhamento de feixe & $\begin{array}{l}\text { O trabalhador situado sobre a plataforma de carga do veículo de } \\
\text { transporte apanha o feixe de erva-mate. }\end{array}$ \\
\hline & $\begin{array}{l}\text { Levantamento de feixe } \\
\text { com haste }\end{array}$ & $\begin{array}{l}\text { O trabalhador situado sobre a plataforma de carga do veículo de } \\
\text { transporte apanha o feixe de erva-mate com o auxílio de uma } \\
\text { haste para sua posterior acomodação. }\end{array}$ \\
\hline & Rolagem de feixe & $\begin{array}{l}\text { O trabalhador situado sobre a plataforma de carga do veículo de } \\
\text { transporte faz a rolagem do feixe de erva-mate para sua posterior } \\
\text { acomodação. }\end{array}$ \\
\hline & Acomodação de feixe & $\begin{array}{l}\text { O trabalhador situado sobre a plataforma de carga do veículo de } \\
\text { transporte faz a organização e acomodação do feixe de erva- } \\
\text { mate. }\end{array}$ \\
\hline
\end{tabular}

Para o levantamento da freqüência cardíaca dos trabalhadores, foi utilizado um monitor de freqüência cardíaca, marca Polar Ou, da Finlândia, que foi fixado nos trabalhadores no início e retirado ao final da jornada de trabalho. Os valores de freqüência cardíaca foram armazenados em intervalos de 15 segundos durante todo o período de trabalho, e, ao final, descarregados em computador por meio de uma interface para compilação e análise dos resultados, conforme metodologia proposta por Apud (1989). Paralelamente, foi realizado um estudo de tempos pelo método de multimomento descrito por Barnes (1977). Esse estudo teve como único objetivo registrar os tempos consumidos em cada atividade física e 
identificar a seqüência das operações realizadas, auxiliando posteriormente as análises dos dados obtidos com o monitor de freqüência cardíaca.

De posse dos dados, determinou-se a carga cardiovascular no trabalho, que corresponde à percentagem da freqüência cardíaca no trabalho em relação à freqüência cardíaca máxima utilizável. Para esse cálculo, foi utilizada a seguinte equação:

$$
C C V=\frac{F C T-F C R}{F C M-F C R} \times 100
$$

em que:

$\mathrm{CCV}=$ Carga cardiovascular $(\%)$;

$\mathrm{FCT}=$ Frequência cardíaca de trabalho;

FCM $=$ Freqüência cardíaca máxima $(220-$ idade $)$;

$\mathrm{FCR}=$ Freqüência cardíaca de repouso.

Em seguida, a carga cardiovascular foi comparada com o limite individual de capacidade cardiovascular de 40\%, sugerido por Apud (1989):

$$
\mathrm{FCL}=0,40 \times(\mathrm{FCM}-\mathrm{FCR})+\mathrm{FCR}
$$

Quando a carga cardiovascular ultrapassou a 40\% (acima da freqüência cardíaca limite), foi necessário reorganizar o trabalho, determinando-se o tempo de recuperação (repouso), obtido por meio da seguinte expressão:

$$
\operatorname{Tr}=\frac{H t \times(F C T-F C L)}{F C T-F C R}
$$

em que:

$\operatorname{Tr}=$ Tempo de repouso (min.);

$\mathrm{Ht}=$ Tempo de trabalho (min.).

Em seguida, determinou-se a carga de trabalho físico em cada atividade e estabeleceram-se os limites aceitáveis para uma "performance" contínua no trabalho. Quando necessário, determinou-se a duração da jornada de trabalho e a duração e freqüência das pausas conforme a capacidade física do trabalhador. Por fim, foi feita a classificação da carga de trabalho conforme proposta de Apud (1997), mostrada na tabela 3 .

Tabela 3. Classificação da carga de trabalho físico através da freqüência cardíaca.

Table 3. Classification of the work according to the cardiac frequency.

\begin{tabular}{lc}
\hline Carga de trabalho físico & Freqüência cardíaca $(\mathbf{b p m})$ \\
\hline Muito leve & $<75$ \\
Leve & $75-100$ \\
Moderadamente pesada & $100-125$ \\
Pesada & $125-150$ \\
Pesadíssima & $150-175$ \\
Extremamente pesada & $>175$ \\
\hline
\end{tabular}

\section{RESULTADOS E DISCUSSÃO}

\section{Carga de trabalho físico geral}

A tabela 4 mostra a freqüência cardíaca média em repouso, no trabalho e a máxima utilizável, a carga cardiovascular, a freqüência cardíaca limite, o tempo necessário para pausas e a classificação do trabalho.

Como pode ser visto, na atividade de poda, a fase de poda principal apresentou maior exigência física, com 111,9 bpm, seguida pela poda secundária, com 108,1 bpm, resultando em cargas 
cardiovasculares de 34,3 e $30,8 \%$, respectivamente. Os valores de freqüência cardíaca estavam abaixo do limite máximo aceitável de 118,0 bpm para esses trabalhadores, sendo todas as fases classificadas como moderadamente pesadas.

$\mathrm{Na}$ atividade de quebra de galhos, as fases de apanhamento, corte e acomodação de galhos nos feixes apresentaram freqüências cardíacas médias de 104,4, 103,7 e 103,3 bpm, resultando em cargas cardiovasculares de 27,8,27,2 e 26,0\%, respectivamente, sendo todas essas fases classificadas como moderadamente pesadas.

$\mathrm{Na}$ atividade de carregamento de caminhão (abaixo), as fases de rolagem e levantamento de feixes para pesagem apresentaram igualmente uma freqüência média de 113,0 bpm e carga cardiovascular média de 33,5\%, quando o limite máximo aceitável foi de 119,5 bpm. Apesar de essas fases terem apresentado maior freqüência cardíaca e serem consideradas de maior exigência física, elas foram também classificadas como moderadamente pesadas.

Tabela 4. Carga física de trabalho média exigida nas atividades de colheita da erva-mate nos meses de janeiro e julho de 2005 .

Table 4. Physical work load required in anise harvest activities in the months of January and July of 2005.

\begin{tabular}{|c|c|c|c|c|c|c|c|}
\hline Atividade & Fases & $\begin{array}{c}\text { FCR } \\
(\text { bpm) }\end{array}$ & $\begin{array}{l}\text { FCT } \\
(\text { bpm) }\end{array}$ & $\begin{array}{l}\text { FCM } \\
(\text { bpm) }\end{array}$ & $\begin{array}{l}\mathrm{CCV} \\
(\%) \\
\end{array}$ & $\begin{array}{c}\text { FCL } \\
(\mathbf{b p m})\end{array}$ & $\begin{array}{c}\text { Classificação do } \\
\text { trabalho } \\
\end{array}$ \\
\hline \multirow{3}{*}{ Poda } & Principal & 75,0 & 111,9 & 182,5 & 34,3 & 118,0 & Mod. Pesado \\
\hline & Secundária & 75,0 & 108,1 & 182,5 & 30,8 & 118,0 & Mod. Pesado \\
\hline & Deslocamento & 75,0 & 106,8 & 182,5 & 29,6 & 118,0 & Mod. Pesado \\
\hline \multirow{4}{*}{$\begin{array}{l}\text { Quebra de } \\
\text { galhos }\end{array}$} & Apanhamento de galhos & 71,5 & 104,4 & 190,2 & 27,8 & 119,0 & Mod. Pesado \\
\hline & Corte de galhos & 71,5 & 103,7 & 190,2 & 27,2 & 119,0 & Mod. Pesado \\
\hline & $\begin{array}{l}\text { Acomodação de galhos } \\
\text { no feixe }\end{array}$ & 71,5 & 103,3 & 190,2 & 26,8 & 119,0 & Mod. Pesado \\
\hline & Deslocamento & 71,5 & 102,2 & 190,2 & 26,0 & 119,0 & Mod. Pesado \\
\hline \multirow{3}{*}{$\begin{array}{l}\text { Carregamento } \\
\text { de caminhão } \\
\text { (abaixo) }\end{array}$} & Rolagem de feixe & 79,3 & 113,0 & 179,8 & 33,5 & 119,5 & Mod. Pesado \\
\hline & $\begin{array}{l}\text { Levantamento de feixe } \\
\text { para pesagem }\end{array}$ & 79,3 & 113,0 & 179,8 & 33,5 & 119,5 & Mod. Pesado \\
\hline & Pesagem de feixe & 79,3 & 104,3 & 179,8 & 24,8 & 119,5 & Mod. Pesado \\
\hline \multirow{4}{*}{$\begin{array}{l}\text { Carregamento } \\
\text { de caminhão } \\
\text { (acima) }\end{array}$} & Apanhamento de feixe & 65,4 & 113,4 & 189,7 & 38,6 & 115,1 & Mod. Pesado \\
\hline & $\begin{array}{l}\text { Levantamento de feixe } \\
\text { com haste }\end{array}$ & 65,4 & 98,5 & 189,7 & 26,6 & 115,1 & Leve \\
\hline & Rolagem de feixe & 65,4 & 112,9 & 189,7 & 38,2 & 115,1 & Mod. Pesado \\
\hline & Acomodação de feixe & 65,4 & 114,0 & 189,7 & 39,1 & 115,1 & Mod. Pesado \\
\hline
\end{tabular}

FCR: Freqüência cardíaca de repouso; FCT: Freqüência cardíaca de trabalho; FCM: Freqüência cardíaca máxima (220 - idade); CCV: Carga cardiovascular; FCL: Freqüência cardíaca limite.

$\mathrm{Na}$ atividade de carregamento de caminhão (acima), a fase de maior exigência física foi a acomodação de feixe, com 114,0 bpm, resultando uma carga cardiovascular de 39,1\%, sendo considerada a atividade de maior exigência física. Em seguida, as fases de apanhamento de feixe para pesagem e rolagem de feixe apresentaram uma freqüência média de 113,4 e 112,9 bpm, resultando em cargas cardiovasculares médias de 38,6 e 38,2\%, respectivamente. Por fim, a fase que apresentou a menor exigência física no trabalho foi o levantamento de feixe com haste, com freqüência cardíaca média de 98,5 bpm e carga cardiovascular média de 26,6\%, sendo classificada como uma atividade leve. Tal resultado mostrou que o uso da haste no auxílio ao carregamento permitiu ao trabalhador empregar menos força, reduzindo seu desgaste físico no trabalho.

A figura 1 mostra o gráfico de freqüência cardíaca no trabalho de um funcionário na atividade de podador. Como pode ser visto, a fase de poda principal apresentou os maiores picos de batimento cardíaco, evidenciando ser a fase de maior exigência física. Todavia, a freqüência cardíaca média no trabalho estava abaixo da freqüência cardíaca limite, não havendo sobrecarga física para os trabalhadores. 


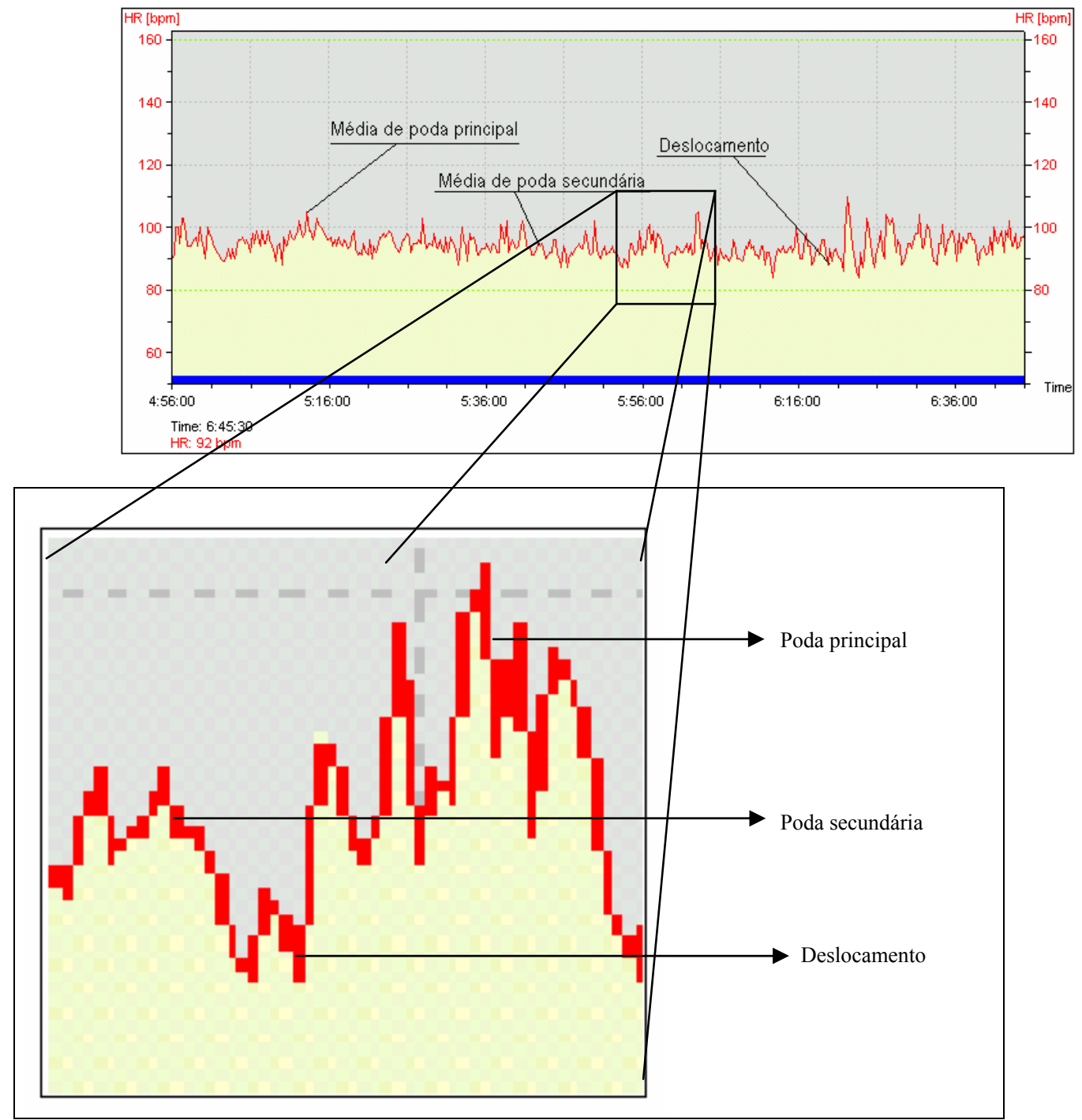

Figura 1. Gráfico de batimentos cardíacos na atividade de poda de erva-mate.

Figure 1. Graph of cardiac beatings in activity of anise pruning.

Segundo Grandjean (1982), quando as avaliações fisiológicas indicam uma carga de trabalho superior à capacidade do trabalhador em determinada condição, torna-se necessário fazer uso de princípios ergonômicos para se obter uma adequada carga de trabalho. Existem duas maneiras eficientes para otimizar a carga de trabalho, modificando o planejamento do sistema ou método de trabalho de modo a reorganizá-lo ergonomicamente ou introduzindo ferramentas ou máquinas auxiliares.

Os resultados obtidos mostraram que nenhuma atividade da colheita de erva-mate ultrapassou o limite de $40 \%$ da carga cardiovascular, não sendo consideradas de elevada exigência física. Porém, em função de informações obtidas em entrevistas com os trabalhadores e pelas diferenças de exigência física entre as atividades, recomenda-se a adoção de algumas medidas ergonômicas por parte da empresa. Uma medida prática é o uso de ferramentas mais leves para uso nas atividades de poda, como facões e foices de pequeno porte e com cabos ergonômicos. Como segunda medida, recomenda-se o estabelecimento de rodízios entre funções, de forma a prevenir lombalgias e o desgaste físico entre os trabalhadores. 
Pela análise de variância, verificou-se que as exigências físicas no trabalho entre as atividades avaliadas foram significativas ao nível de probabilidade de $95 \%$ (Tabela 5).

Tabela 5. Análise da variância das atividades da colheita de erva-mate.

Table 5. Analysis variance of the activities of the anise harvest.

\begin{tabular}{lcccc}
\hline Fonte de variação & GL & SQ & QM & F \\
\hline Tratamentos & 3 & 625,6 & 208,5 & $3,14^{*}$ \\
Resíduo & 46 & 3051,3 & 66,3 & \\
\hline Total & 49 & 3676,9 & & \\
\hline (*) Significativo a 95\% de probabilidade. & & &
\end{tabular}

Foi verificado que as atividades de carregamento de caminhão (abaixo), carregamento de caminhão (acima) e poda não apresentaram diferenças significativas entre si, pelo teste de Tukey com significância de 5\%, sendo consideradas atividades de mesma exigência física. Somente a atividade de quebra de galhos diferiu significativamente das demais, sendo consideradas de menor exigência física (Tabela 6).

Tabela 6. Valores médios de freqüência cardíaca e teste Tukey nas atividades da colheita de erva-mate. Table 6. Average values of cardiac frequency and test Tukey in the harvest anise activities.

\begin{tabular}{lcccc}
\hline Atividade & FCT & Teste Tukey & C.V. (\%) & D.P. \\
\hline Carregamento de caminhão (abaixo) & 112,0 & A & 9,0 & 10,051 \\
Carregamento de caminhão (acima) & 111,7 & A & 8,7 & 9,060 \\
Poda & 108,6 & A & 5,3 & 5,763 \\
Quebra de galhos & 103,6 & B & 7,3 & 8,140 \\
\hline
\end{tabular}

As médias seguidas por mesma letra não diferem estatisticamente entre si, pelo teste de Tukey com significância de $5 \%(\mathrm{p}<0,05)$.

\section{Carga de trabalho físico por período}

A tabela 7 mostra a freqüência cardíaca, a carga cardiovascular, o tempo de pausas e a classificação do trabalho nos diferentes períodos em que se realizou a coleta dos dados. Como pode ser visto, de modo geral, em todas as atividades analisadas, a freqüência cardíaca no trabalho foi superior no mês de janeiro (verão), quando as condições climáticas são mais adversas. Nesse período, a temperatura média era de $26,6^{\circ} \mathrm{C}$ e a umidade relativa de $62,0 \%$, enquanto que, no inverno, a temperatura média era de $14,3{ }^{\circ} \mathrm{C}$, com umidade relativa de $70,6 \%$.

As fases de apanhamento, rolagem e acomodação de feixe na atividade de carregamento do veículo de transporte (acima) apresentaram as maiores exigências físicas, com cargas cardiovasculares acima do limite máximo de $40 \%$. Tal resultado mostrou a necessidade do estabelecimento de uma pequena pausa de recuperação a cada hora trabalhada. $\mathrm{Na}$ atividade de quebra de galhos, as fases de apanhamento, corte e acomodação de galhos no feixe apresentaram freqüências cardíacas médias no trabalho de 104,4, 103,7 e 103,3 bpm, resultando em cargas cardiovasculares de 27,8, 27,2 e 26,0\%, respectivamente, sendo essas classificadas como moderadamente pesadas.

$\mathrm{Na}$ atividade de carregamento de caminhão (abaixo), as fases de rolagem e levantamento de feixe para pesagem apresentaram igualmente uma freqüência média no trabalho de 113,0 bpm, com carga cardiovascular média de 33,5\%, quando o limite máximo aceitável foi de 119,5 bpm. Apesar de as fases terem apresentado elevada freqüência cardíaca e terem sido consideradas de maior exigência física, elas foram também classificadas como moderadamente pesadas.

A figura 2 ilustra a carga cardiovascular média nos diferentes períodos de coleta de dados. Como visto, todas as atividades tiveram uma carga cardiovascular superior no mês de janeiro, mostrando ser este o período de maior exigência física. 
Tabela 7. Carga física de trabalho exigida na colheita da erva-mate em janeiro e julho.

Table 7. Physical work load required in anise harvest in the months of January and July.

\begin{tabular}{|c|c|c|c|c|c|c|c|c|}
\hline Atividade & Fases & $\begin{array}{c}\text { FCR } \\
\text { (bpm) }\end{array}$ & $\begin{array}{c}\text { FCT } \\
\text { (bpm) }\end{array}$ & $\begin{array}{l}\text { FCM } \\
(\text { bpm) }\end{array}$ & $\begin{array}{l}\mathrm{CCV} \\
(\%)\end{array}$ & $\begin{array}{c}\text { FCL } \\
(\text { bpm) }\end{array}$ & $\begin{array}{c}\text { Tr } \\
(\mathrm{min})\end{array}$ & $\begin{array}{c}\text { Classificação } \\
\text { trabalho }\end{array}$ \\
\hline \multirow{8}{*}{ Poda } & \multicolumn{8}{|c|}{ Janeiro } \\
\hline & Principal & 75,0 & 112,8 & 182,0 & 35,3 & 117,8 & - & Mod. Pesado \\
\hline & Secundária & 75,0 & 110,0 & 182,0 & 32,7 & 117,8 & - & Mod. Pesado \\
\hline & Deslocamento & 75,0 & 107,8 & 182,0 & 30,6 & 117,8 & - & Mod. Pesado \\
\hline & \multicolumn{8}{|c|}{ Julho } \\
\hline & Principal & 75,0 & 108,1 & 184,0 & 30,3 & 118,6 & - & Mod. Pesado \\
\hline & Secundária & 75,0 & 105,0 & 184,0 & 27,5 & 118,6 & - & Mod. Pesado \\
\hline & Deslocamento & 75,0 & 103,4 & 184,0 & 26,0 & 118,6 & - & Mod. Pesado \\
\hline \multirow{10}{*}{$\begin{array}{l}\text { Quebra } \\
\text { de galhos }\end{array}$} & \multicolumn{8}{|c|}{ Janeiro } \\
\hline & $\begin{array}{l}\text { Apanhamento } \\
\text { de galhos }\end{array}$ & 63,0 & 98,3 & 194,0 & 27,7 & 115,4 & - & Leve \\
\hline & Corte de galhos & 63,0 & 100,0 & 194,0 & 28,2 & 115,4 & - & Mod. Pesado \\
\hline & $\begin{array}{l}\text { Acomodação de } \\
\text { galhos no feixe }\end{array}$ & 63,0 & 98,7 & 194,0 & 27,2 & 115,4 & - & Leve \\
\hline & Deslocamento & 63,0 & 101,0 & 194,0 & 29,2 & 115,4 & - & Mod. Pesado \\
\hline & \multicolumn{8}{|c|}{ Julho } \\
\hline & $\begin{array}{l}\text { Apanhamento } \\
\text { de galhos }\end{array}$ & 76,2 & 105,0 & 187,8 & 28,8 & 120,8 & - & Mod. Pesado \\
\hline & Corte de galhos & 76,2 & 104,7 & 187,8 & 25,5 & 120,8 & - & Mod. Pesado \\
\hline & $\begin{array}{l}\text { Acomodação de } \\
\text { galhos no feixe }\end{array}$ & 76,2 & 104,4 & 187,8 & 25,3 & 120,8 & - & Mod. Pesado \\
\hline & Deslocamento & 76,2 & 102,6 & 187,8 & 23,7 & 120,8 & - & Mod. Pesado \\
\hline \multirow{8}{*}{$\begin{array}{l}\text { Carregamento } \\
\text { de caminhão } \\
\text { (abaixo) }\end{array}$} & \multicolumn{8}{|c|}{ Janeiro } \\
\hline & Rolagem de feixe & 79,0 & 114,8 & 180,6 & 35,2 & 119,6 & - & Mod. Pesado \\
\hline & $\begin{array}{l}\text { Levantamento } \\
\text { de feixe para } \\
\text { pesagem }\end{array}$ & 79,0 & 113,6 & 180,6 & 34,1 & 119,6 & - & Mod. Pesado \\
\hline & Pesagem de feixe & 79,0 & 102,5 & 180,6 & 23,1 & 119,6 & - & Mod. Pesado \\
\hline & \multicolumn{8}{|c|}{ Julho } \\
\hline & Rolagem de feixe & 80,0 & 108,0 & 176 & 29,2 & 118,4 & - & Mod. Pesado \\
\hline & $\begin{array}{l}\text { Levantamento de } \\
\text { feixe para } \\
\text { pesagem }\end{array}$ & 80,0 & 106,2 & 176 & 27,3 & 118,4 & - & Mod. Pesado \\
\hline & Pesagem de feixe & 80,0 & 105,5 & 176 & 26,5 & 118,4 & - & Mod. Pesado \\
\hline \multirow{10}{*}{$\begin{array}{l}\text { Carregamento } \\
\text { de caminhão } \\
\text { (acima) }\end{array}$} & \multicolumn{8}{|c|}{ Janeiro } \\
\hline & $\begin{array}{l}\text { Apanhamento } \\
\text { de feixe }\end{array}$ & 63,3 & 115,4 & 189,8 & 41,2 & 113,9 & $1: 44$ & Mod. Pesado \\
\hline & $\begin{array}{l}\text { Levantamento de } \\
\text { feixe com haste }\end{array}$ & 63,3 & 99,7 & 189,8 & 28,8 & 113,9 & - & Leve \\
\hline & Rolagem de feixe & 63,3 & 114,8 & 189,8 & 40,7 & 113,9 & $1: 17$ & Mod. Pesado \\
\hline & $\begin{array}{l}\text { Acomodação de } \\
\text { feixe }\end{array}$ & 63,3 & 116,2 & 189,8 & 41,8 & 113,9 & $2: 17$ & Mod. Pesado \\
\hline & \multicolumn{8}{|c|}{ Julho } \\
\hline & $\begin{array}{l}\text { Apanhamento de } \\
\text { feixe }\end{array}$ & 66,0 & 103,8 & 189,5 & 30,6 & 115,4 & - & Mod. Pesado \\
\hline & $\begin{array}{l}\text { Levantamento de } \\
\text { feixe com haste }\end{array}$ & 66,0 & 96,6 & 189,5 & 24,8 & 115,4 & - & Leve \\
\hline & Rolagem de feixe & 66,0 & 106,7 & 189,5 & 32,9 & 115,4 & - & Mod. Pesado \\
\hline & $\begin{array}{l}\text { Acomodação de } \\
\text { feixe }\end{array}$ & 66,0 & 103,4 & 189,5 & 30,2 & 115,4 & - & Mod. Pesado \\
\hline
\end{tabular}

FCR: Freqüência cardíaca de repouso; FCT: Freqüência cardíaca de trabalho; FCM: Freqüência cardíaca máxima (220 - idade); CCV: Carga cardiovascular; FCL: Freqüência cardíaca limite. 


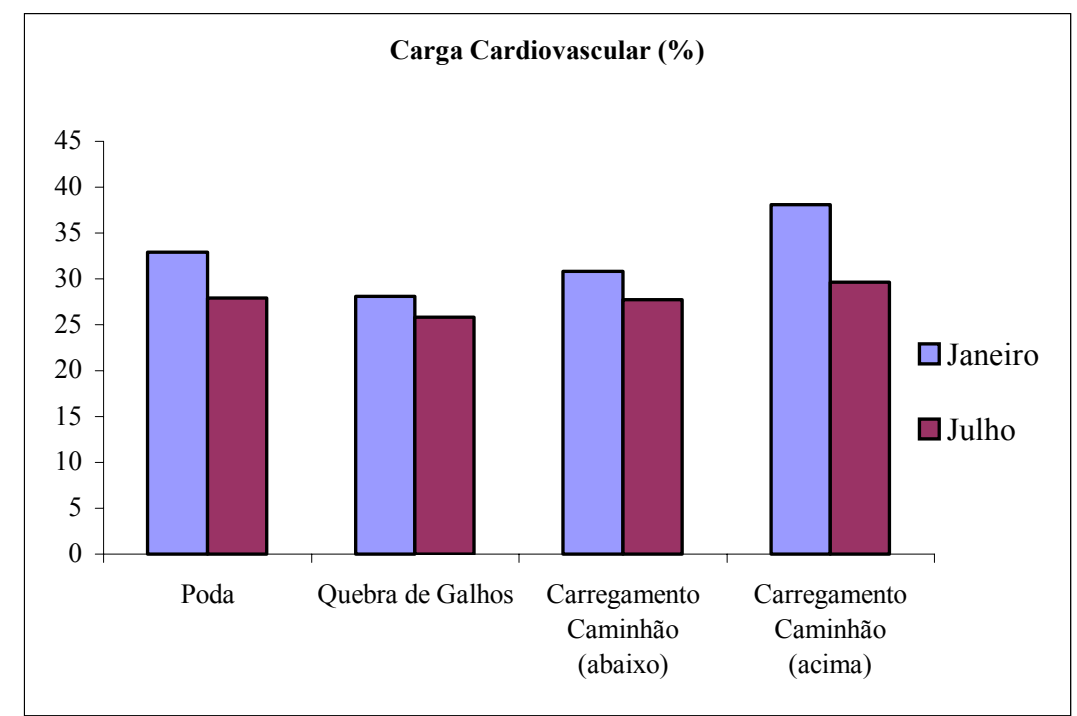

Figura 2. Carga cardiovascular média por atividade em diferentes períodos.

Figure 2. Average cardiovascular load for activity in different periods.

\section{CONCLUSÕES}

Nas condições de desenvolvimento deste trabalho e com base na análise e discussão dos resultados, a presente pesquisa permitiu chegar às seguintes conclusões:

- Todas as atividades da colheita de erva-mate apresentaram no geral, baixa exigência física, sendo classificadas como moderadamente pesadas, com exceção da fase de levantamento de feixe com haste na atividade de carregamento de caminhão (acima), classificada como atividade leve.

- A baixa exigência física requerida na fase de levantamento do feixe de erva-mate na atividade de carregamento de caminhão (acima) mostrou que o uso da haste reduziu o desgaste físico do trabalhador.

- Os valores de carga cardiovascular não ultrapassaram o limite máximo de $40 \%$, não tendo havido sobrecarga física aos trabalhadores, sendo, portanto, desnecessária a adoção de medidas ergonômicas. Porém, em função de entrevistas realizadas com os trabalhadores e pelos valores diferenciados de carga cardiovascular obtidos, recomenda-se o uso de ferramentas mais leves e com cabos ergonômicos para a realização das podas, montagem de feixes menores, facilitando o carregamento da erva-mate, e introdução de rodízios entre funções, de forma a prevenir lombalgias e desgastes físicos nos trabalhadores.

- As atividades de carregamento de caminhão (abaixo), carregamento do caminhão (acima) e poda não apresentaram diferenças significativas entre si, sendo consideradas de mesma exigência física.

- Analisando as exigências físicas das atividades de colheita de erva-mate em relação aos diferentes períodos do ano, verificou-se que a maior exigência física ocorreu durante o verão, quando as condições climáticas são mais adversas comparativamente ao período de inverno.

\section{REFERÊNCIAS}

APUD, E. Human biological methods for ergonomics research in forestry. In: ILO. Guidelines on ergonomic study in forestry. Genebra, 1989. 110p.

APUD, E. Temas de ergonomia aplicados al aumento de la productividadde la mano de obra en cosecha forestal. In: SIMPÓSIO BRASILEIRO SOBRE COLHEITA E TRANSPORTE FLORESTAL, 3, 1997, Vitória: SIF/UFV, 1997. p. 46-60.

BARNES, R. M. Estudos de movimentos e de tempos - projeto e medida do trabalho. São Paulo, Edgard Blucher. 1977. 744p. 
COUTO, H. A. Ergonomia aplicada ao trabalho - o manual técnico da máquina humana. Belo Horizonte: Ergo Editora, 1995, v. 1.353p.

FIEDLER, N. C.; MENEZES, N. S.; MINETTI, L. J.; MARTINS, I. S. Análise da exigência física do trabalho em fábricas de móveis do Distrito Federal. Revista Árvore, V. 27, n. 6., 2003. p.879-885.

GRANDJEAN, E. Fitting the task to the man - An Ergonomic Approach. London, Taylor \& Francis, 1982. 379p.

GRANDJEAN, E. Fitting the task to the man. London: Taylor \& Francis, 1988. 363p.

IIDA, I. Ergonomia; projeto e produção. São Paulo: Edgard Blucher, 1990. 465p.

RODIGHERI, H. R. Rentabilidade econômica comparativa entre plantios florestais e sistemas agroflorestais com erva-mate, eucalipto e pinus e as culturas do feijão, milho, soja e trigo. Colombo, PR: EMBRAPA, 1997. 36p. (Circular Técnica, 26). 